\title{
Redes de Arte e Cultura nas universidades públicas em tempos de pandemia
}

DOI: https://doi.org/10.22409/pragmatizes.v10i19.42633

Michele Dacas ${ }^{1}$

Resumo: Se por um lado as universidades públicas têm atuado em diferentes frentes no combate ao novo coronavirus, por outro, elas seguem sendo alvos de uma política de desmonte da educação. Nos últimos anos os avanços tecnológicos também abriram espaço para a circulação de notícias falsas ou ideias impregnadas por um sentimento antiintelectualista e anticientificista. Esses discursos têm corrompido a parte mais conservadora da sociedade a desvalorizar os serviços e as instituições públicas em geral, principalmente na educação, na cultura e na saúde e com isso legitimado medidas de austeridade nesses campos. Entretanto, mesmo neste cenário de pandemia que assolou o Brasil, temos na universidade pública, junto ao sistema Único de Saúde (SUS), umas das instituições fundamentais para enfrentamento da crise sanitária. São várias as frentes em que as universidades públicas atuam em todo o país para combater o covid-19, contribuem com estudos epidemiológicos, práticas de saúde coletiva, acolhimentos psicológicos, desenvolvimento de equipamentos através das engenharias e também com a circulação de iniciativas de arte e a cultura. Esta última recentemente reconhecida pela Organização mundial da Saúde (OMS) como área que deve ser incluída no sistema sanitário como política de saúde por proporcionar bem estar e melhorar as condições de enfrentamento a algumas doenças. Neste sentido que muitas universidades públicas estão utilizando de suas redes colaborativas e acúmulos de práticas e conhecimentos em arte e cultura para promover virtualmente o bem estar durante a pandemia. São estas ações específicas que atravessam o campo da cultura e da educação pública por meio da apropriação das novas tecnologias de comunicação em um contexto de crise sanitária que serão base de reflexão deste estudo.

Palavras-Chave: redes virtuais; universidades públicas; arte e cultura; covid-19

\section{Redes de Arte y Cultura en las universidades públicas en tiempos de pandemia}

Resumen: Si, por un lado, las universidades públicas han actuado en diferentes frentes en la lucha contra el nuevo coronavirus, por otro, continúan siendo objetos de una política de desmantelamiento de la educación. En los últimos años, los avances tecnológicos también han abierto un espacio para la circulación de noticias falsas o ideas impregnadas de un sentimiento anti-intelectual y anticientífico. Esos discursos han corrompido a la parte más conservadora de la sociedad para devaluar los servicios públicos y las instituciones en general, principalmente las de educación, cultura y salud, y así pues, legitimar las medidas de austeridad en estos campos. Sin embargo, incluso en este escenario de pandemia que actualmente ha afectado Brasil, tenemos en la universidad pública, junto con ello Sistema Único de Salud (SUS), una de las instituciones fundamentales para enfrentar la crisis de salud. Hay muchas frentes en las cuales las universidades públicas trabajan por todo el país para combatir el covid-19, contribuyen con estudios epidemiológicos, prácticas colectivas de salud, atención psicológica, desarrollo de equipos a través de la ingeniería y también a través de la

\footnotetext{
${ }^{1}$ Michele Dacas. Doutora em Comunicação Social pela Universidade Federal de Minas Gerais, relações públicas e gestora cultural na Universidade Federal da Integração Latino-Americana / UNILA, Paraná, Brasil. E-mail: michele.dacas@gmail.com - https://orcid.org/0000-0001-6330-7454
} 
circulación de iniciativas artísticas y culturales. Este último fue reconocido recientemente por la Organización Mundial de la Salud (OMS) como un área que debería incluirse en el sistema de salud como una política de salud para proporcionar bienestar y mejorar las condiciones para hacer frente a algunas enfermedades. En este sentido, muchas universidades públicas están utilizando sus redes de colaboración y acumulaciones de prácticas y conocimientos en arte y cultura para promover virtualmente el bienestar durante la pandemia. Son estas acciones específicas que cruzan el campo de la cultura y la educación pública a través de la apropiación de las nuevas tecnologías de comunicación en un contexto de crisis de salud que serán la base para la reflexión en este estudio.

Palavras clave: redes virtuales; universidades públicas; arte y cultura; covid-19

\title{
Art \& Culture Networks in Public Universities in Times of Pandemic
}

\begin{abstract}
If, on the one hand, public universities have been active in the front line of combat to the new coronavirus, in the other, the policy of dismantling public education continues to target them. In recent years, technological advances have also opened space for the circulation of fake news or ideas impregnated with anti-intellectual and anti-scientific feelings. Those narratives have been polluting the most conservative part of society towards belittling the overall public institutions and the service they provide, in particular the educational, cultural, and public health, legitimizing the austerity measures in those fields. However, even in this pandemic scenario that is plaguing Brazil, we found in the public universities, alongside with the universal public health system (SUS), one pillar for facing the current sanitary crisis. There are several fronts on witch public universities work across the country to combat COVID-19, by contributing to epidemiological studies, collective health practices, psychological care, development of equipment through engineering, and also with the circulation of art and cultural initiatives. The sanitary system into health policies must include the latter recently recognized by the World Health Organization (WHO) seeing as it provides well-being and improves the condition for coping with some diseases. In this sense, many public universities are using their collaborative networks and accumulations of practices and knowledge in art and culture to promote virtually wellbeing during the pandemic. It is these specific actions that cross the field of culture and public education through the appropriation of unknown communication technologies in a health crisis that will be the basis for reflection in this study.
\end{abstract}

Keywords: virtual networks; public universities; art and culture; COVID-19.

\section{Redes de Arte e Cultura nas universidades públicas em tempos de pandemia}

\section{Introdução}

Com o objetivo de compreender

os processos de enfrentamento ao

covid-19 através de diferentes

plataformas promovidas pelas

universidades públicas,

especificamente na mediação virtual

de redes de arte e cultura, que este

estudo busca relacionar esta atuação ao contexto de crise política e desmonte da educação e da cultura pelo qual essas instituições são simultaneamente atravessadas. Para refletir sobre esta questão a estrutura metodológica seguirá com uma combinação de instrumentos de análise e perspectivas para adaptar um arranjo compatível aos devires 


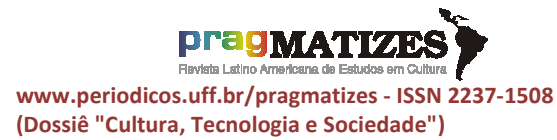

encontrados na diversidade de conteúdos, formatos e sujeitos presentes nas mediações culturais em rede, organizadas pelas universidades públicas neste período de isolamento social. Quando tratamos deste conjunto multimodal ao qual denominamos como mediações culturais em redes virtuais, nos referimos à interlocução entre universidades e sociedade por meio de plataformas de conteúdos, interações, repertórios e públicos destinatários. Portanto, a reflexão deste estudo irá combinar a análise de múltiplos casos e as respectivas discussões bibliográficas suscitadas pelos mesmos, considerando o contexto social e político ao qual se inscrevem e são influenciadas essas iniciativas de arte e cultura online, perpetuadas pelas universidades públicas como uma entre as formas de combater a pandemia porque auxiliam no fortalecimento da prática preventiva do isolamento.

Portanto propomos como perspectiva metodológica central a internet como campo de análise no qual o pesquisador realiza a sua imersão e coleta de dados por meio da navegação na interface online, conforme aponta Fragoso, Recuero e Amaral (2012). Imersão a qual permite flexibilidade ao pesquisador no campo da internet, podendo traçar panoramas de análise que contemplem diferentes eixos em relação a linguagem, apropriação tecnológica, práticas de consumo e socialização online, entre outras. Com base nas perspectivas metodológicas levantadas pelas autoras, nos interessa como diretriz a abordagem praxeológica ${ }^{2}$ que entende a internet como mídia, dotada de práticas e estratégias comunicacionais que dialogam com determinadas culturas, envolvendo narrativas, agenciamentos e infraestruturas. E a abordagem que compreende a internet como artefato cultural que integra os âmbitos online e offline, que a observa como elemento da cultura e não como algo à parte. 'A ideia de artefato cultural compreende que existem diferentes significados culturais em diferentes objetos de uso" (AMARAL, FRAGOSO, RECUERO, 2012, p. 42). Dessa forma, o objeto de estudo implica na análise da conjuntura e a

\footnotetext{
${ }^{2}$ Segundo as autoras (2012, p.44), a abordagem proposta pelo grupo de Barcelona é embasada no conceito de praxeologia que é a teoria ou a ciência da ação que procura estabelecer as leis que governam a ação humana.
} 


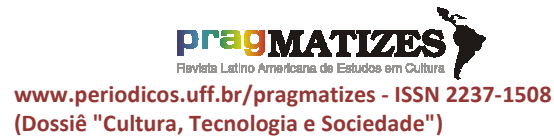

partir disso, a valorização dos dados para a elaboração de uma interpretação com base na constituição de categorias norteadas pela aliança entre observação e teorias.

Sendo assim, a constituição do corpus deste trabalho contempla a experiência de três universidades federais que implementaram iniciativas de arte e cultura como meio de amenizar efeitos negativos para a população durante o isolamento social, instrumento de prevenção ao novo coronavirus implementado em vários países e recomendado pela $\mathrm{OMS}^{3}$. Faremos aqui uma imersão em sites, blogs, plataformas streaming e redes sociais do Núcleo cultural da UFCSPA $^{4}$, do Departamento de Difusão Cultural da UFRGS ${ }^{5}$ e do Centro Cultural UFSJ ${ }^{6}$, para coletar e analisar os objetivos, os processos, os conteúdos e interlocutores envolvidos

\footnotetext{
${ }^{3}$ Organização Mundial da Saúde

${ }^{4}$ Universidade Federal de Ciências da Saúde de Porto Alegre (www.ufcspa.edu.br/index.php/ultimasnoticias/34-noticias/8328-conexao-cultura-umespaco-de-manifestacao-cultural-em-rede)

${ }^{5}$ Universidade Federal do Rio Grande do Sul (www.ufrgs.br/difusaocultural/ddc-ofereceaulas-performances-e-resgata-a-sua-historiaem-meio-a-quarentena)

${ }^{6}$ Universidade Federal de São João Del Rei (www.ufsj.edu.br/noticias_ler.php?codigo_notic ia $=7886$ )
}

nessas ações. Essas plataformas mesmo tendo sua programação conduzida e suas estruturas organizadas por determinadas instituições de ensino superior, apresentam conforme Castells (2009) a convergência de uma rede horizontal, com caráter e forma multimodal, devido à colaboratividade de autorias diversas, e multiplicidade de formatos midiáticos. Entretanto, com base na perspectiva metodológica exposta esses elementos das plataformas de arte e cultura serão interpretados conforme 0 contexto social e político e a grave crise sanitária em que elas se inscrevem. Também autores como Manuel Castells (2009), observam a internet como um campo que integra, influencia e é afetado pelo contexto, não se tratando assim de um mundo virtual, mas de "una virtualidad real integrada en otras formas de interacción en una vida diaria cada vez más híbrida" (CASTELLS, 2009, p.105)

Realidade offline: qual o contexto sociopolítico das universidades públicas? 


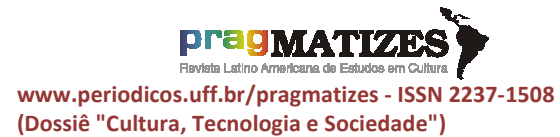

Desde a instauração dos cortes de gastos com saúde e educação em 2016 e o recente contingenciamento orçamentário das instituições de ensino superior, não há previsão para impressão da publicação cultural. Os últimos exemplares impressos da revista foram financiados pelo extinto Ministério da Cultura (MinC), através de programa $^{7}$ voltado para as universidade públicas, para subsidiar seus próprios projetos, planos e políticas culturais, que reconhecia 0 potencial dessas instituições de ensino para o fomento de toda a cadeia produtiva da arte e da cultura em suas esferas de abrangência.

Segundo Gobira, Rolla, Simon da Silveira e Lemos, (2017) desde a abertura democrática, e especialmente no início do século XXI, tivemos uma mudança nos olhares políticos sobre a cultura. Com o impulso das novas tecnologias e a pressão dos movimentos culturais, passa a ser estruturada a pasta administrativa e as respectivas políticas para promover a produção e o acesso à arte e à cultura. Também o desenvolvimento das diretrizes econômicas para subsidiar a produção criativa da cultura passam a legitimar os investimentos para a sua produção em caráter local e, ao mesmo tempo, com alcance global.

\footnotetext{
${ }^{7}$ Programa Mais Cultura nas Universidades.
}

Com isso, surge em 2010, através da Lei o 12.343, o plano nacional de cultura (PNC), onde ocorre uma convergência de iniciativas e são estabelecidos parâmetros e metas para a assegurar 0 direito ${ }^{8}$ à arte e à cultura no país. Esse plano influencia e atravessa outras instâncias públicas, para além das esferas municipais, estaduais e do próprio MinC, e alcança as universidades federais que começaram a despontar como atores culturais e a criar também seus próprios planos e políticas institucionais de cultura. Incentivadas também por programas como o já citado "Mais Cultura nas Universidades".

Entretanto esse panorama retrocedeu, tanto em interesse e apoio do Estado, como na manutenção e ampliação de investimentos na área da cultura. Com a mudança de cenário político e o aprofundamento das crises nas instituições democráticas, testemunhamos 0 desmonte da educação e da cultura, o que inclui a conversão do MinC em uma secretaria subordinada ao ministério do Turismo. Também a substituição de nomes técnicos em cargos diretivos de órgãos

\footnotetext{
${ }^{8}$ A Constituição brasileira, em seu artigo 215 , prevê que "O Estado garantirá a todos o pleno exercício dos direitos culturais e acesso às fontes da cultura nacional, e apoiará e incentivará a valorização e a difusão das manifestações culturais" (BRASIL, 2016).
} 


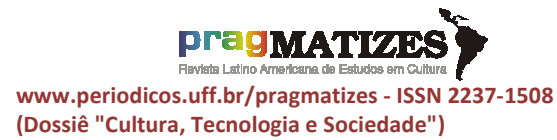

se posicionando e colocando à disposição da sociedade todo o seu acúmulo de recursos humanos e materiais para fazer um enfrentamento à crise impulsionada pelo vírus.

Apesar de todo o programa de com a crise sanitária vivenciada pela expansão mundial do covid-19, toda a situação da já enfraquecida estrutura dos setores culturais e da categoria de trabalhadores criativos se agrava.

Ainda assim, educação e cultura, dois campos fundamentais da vida, ambos desestabilizados por políticas de desmonte seguem paradoxalmente avançando em meio à crise sanitária e econômica. Criam formas de reconfigurar a sua atuação e valendo-se das novas tecnologias tornam-se imprescindíveis para 0 combate das desigualdades, para assegurar os direitos humanos de qualquer cidadão à informação, à cultura, à saúde e à vida. São as universidades públicas que junto a organismos da saúde públicos estão

\footnotetext{
9 "O Fundo Nacional da Cultura (FNC) é a principal ferramenta de apoio direto à cultura do Governo Federal. É um dos três pilares da Lei de Incentivo à Cultura (a Lei Rouanet), principal estrutura de fomento a projetos culturais no país. O programa recebe investimento do próprio governo, e a aplicação de recursos é feita por meio de convênios, editais e premiações. Em 2010, o fundo foi responsável por injetar 344 milhões de reais na cultura brasileira. Foram 461 iniciativas contempladas. Já no ano passado, o primeiro da gestão Bolsonaro, foram apenas sete projetos contemplados, totalizando $\mathrm{R} \$ 995$ mil'. fonte: observatório Nacional da cultura.
} contingenciamento, estão na linha de frente com atendimento hospitalar, difusão de informações, acolhimento psicológico, pesquisas, análises de conjuntura, e outras medidas de melhoramentos das condições de contenção da pandemia, atuando diretamente com a salvaguarda de seus territórios. As universidades federais têm colocado toda a sua produção acadêmica e científica a serviço de suprir as necessidades da população, auxiliando os profissionais de saúde com estudos sobre os impactos da pandemia na sociedade, desenvolvimento de respiradores mecânicos, EPIs (equipamentos de proteção individual).

Essa atuação só é possível porque a autonomia universitária permite que mesmo o poder executivo tomando medidas contrárias às recomendadas pela comunidade científica, o compromisso dessas instituições mantém-se alinhado à produção e circulação do conhecimento para o bem estar da população e preservação da biodiversidade. Quanto mais 


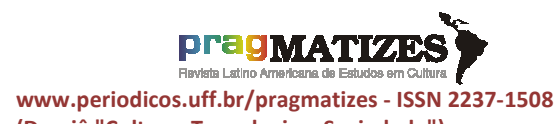

(Dossiê "Cultura, Tecnologia e Sociedade") assegurada a democratização do acesso, a gratuidade, e a autonomia da universidade pública, em maior proporção estará garantida a atuação dessas instituições a serviço do interesse público. Portanto justificar a redução do investimento público nas universidades brasileiras através de propostas que visam trazer "inovação" a partir do financiamento privado é submeter toda a sua contribuição para o desenvolvimento local sustentável pautado nas demandas da sociedade a um modelo de negócio. Por não estarem submetidas ao mercado, que em uma crise sanitária-políticaeconômica-social como a que estamos vivenciando, as principais iniciativas de prevenção e combate à epidemia vêm das universidades públicas e não das instituições de ensino superior privadas, nas quais 0 modelo pedagógico objetiva finalidades mercadológicas, tanto em sua formação, quanto no seu escasso campo da pesquisa. Portanto, popularizar a defesa da universidade pública para que sua atuação ocorra em prol da ética e do compromisso com a sociedade é uma

tarefa complexa, mas imprescindível para fortalecer as lutas sociais em prol do bem viver dos povos, da crítica à colonialidade do saber e da colonialidade do poder decorrente do racismo. Iniciativa crucial, também, para a afirmação plena das capacidades criadoras dos povos diante de todas as formas de antissecularismo, opressão, e de exploração operacionalizadas tanto pelo conhecimento produzido para dominar e subjugar as pessoas e a natureza, e, nos tempos atuais, como pela difusão do irracionalismo que pretende interditar o próprio pensamento científico. A ciência e a tecnologia podem ser criadas com base na ética da produção do conhecimento, procurando respostas e formas de intervenção que possibilitem o bem viver dos povos, mas podem, também, estar inseridas em dispositivos de poder que tornam o conhecimento uma ferramenta em prol de fins particularistas, bélicos, e mesmo em favor de aparatos técnico científicos que comprometem a biodiversidade e a vida humana. (LEHER, 2019,p.39)

Segundo Leher (2019), a principal narrativa para desqualificar as universidades públicas pelo atual governo segue duas nervuras principais, uma que atribui a elas um lugar de doutrinação ideológica, de predominância do que a ultradireita internacional denominou supostamente por "marxismo cultural'. $E$ a outra que afirma o baixo retorno das universidades em relação aos altos investimentos públicos do governo. Narrativas assim, além de permeadas por um sentimento anticientificista, antiintelectualista e anticulturalista têm por base a classificação em rankings internacionais que estabelecem critérios a partir da "força relativa dos países nas relações de poder mundial" (LEHER, 2019, p.29). Também ignoram os cortes orçamentários, e 


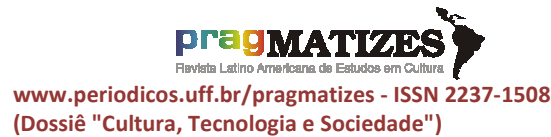

processos repressivos dos quais as universidades brasileiras foram alvos na época da ditadura de 1964-1980. Desconsideram outros fatores históricos determinantes para 0 fortalecimento das universidades europeias e estadunidenses que diferem do tardio processo de consolidação das universidades brasileiras. processos de revolução burguesa nos EUA, Inglaterra e França, e com especificidades, na Alemanha, abriram vias para projetos autopropelidos de nação. A industrialização, no século XIX, se deu a partir de objetivos e meios nacionais: por isso, o apoio ativo do estado às suas grandes universidades engendrou notável fortalecimento da pesquisa nestas. ainda nos dias de hoje, esses estados alocam grandes somas de recursos em suas universidades. $O$ recente anúncio do governo alemão de recriação da infraestrutura acadêmica do país, aportando bilhões de euros, se soma aos investimentos feitos nos EUA e na China. A Harvard Management Company declara um fundo de U\$\$ 37,1 bilhões (Moody, 2018), quase 3 vezes 0 das 63 universidades federais juntas. (LEHER, 2019, p.29)

Portanto as duas narrativas, a ideológica e a da insuficiência de resultados legitima o apoio de uma parte da sociedade a medidas governamentais como os cortes inscritos na emenda Constitucional $\mathrm{n}$. $95 / 2016^{10}$, o bloqueio de $30 \%$ dos

\footnotetext{
${ }^{10}$ Aprovada no governo Temer, é a medida que reduz, ano a ano, o equivalente a $0,8 \%$ do
}

recursos de todas as federais ao mesmo tempo em que lançam um pacote chamado future-se ${ }^{11}$, que desobriga o Estado a custear as universidades públicas. Essas medidas somam-se aos ataques em outras frentes como as tentativas de debilitar a autonomia universitária como o Decreto $9.794^{12}$ de 15/05/2019 que possibilita intervenção do governo na escolha de cargo diretivos e o decreto 9.7954, de 11/04/2019, que extingue cargos efetivos das áreas administrativas das universidades.

Paradoxalmente o caminho que pavimenta a defesa das universidades públicas e o seu protagonismo social se estabelece nesse que é o período de mais grave crise e desestabilização das bases democráticas no Brasil desde a ditadura. Nesse momento em que as universidades sofrem intensos cortes devido à redução no investimento da educação pública superior, são protagonistas no

PIB dos gastos públicos com as políticas sociais e os investimentos públicos. (LEHER, 2019, p.31)

${ }^{11}$ É o estrangulamento orçamentário e a conversão das universidades em agências captadoras de (inexistentes) projetos de pesquisa e desenvolvimentos privados. (LEHER, 2019, p.31)

${ }^{12}$ Estabelece que a nomeação para os cargos de direção das universidades federais devem ser precedidos de análise dos nomes pelo governo federal, instituindo o sistema Integrado de Nomeações e Consultas. (LEHER, 2019, p.32) 


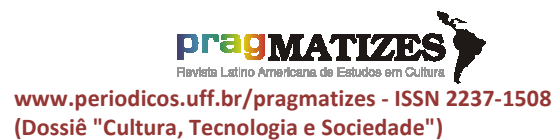

combate ao covid-19 no país. Mesmo com os campus vazios, é possível navegar pelos sites dessas instituições e observar uma série de medidas que vão desde plantão de atendimento de saúde, acolhimento psicológico, programas de difusão de esportes, arte e cultura, divulgação científica, dados e mapeamentos sobre a pandemia, campanhas de doação e informações úteis entre outros. Além do enfrentamento em hospitais e bairros com equipes de profissionais da saúde da universidade, é por meio de plataformas online que essas instituições buscam amenizar os efeitos do isolamento social, e asseguram o bem estar da população; para aqueles que estão em quarentena, há disponibilidade de acervos e cursos online com temáticas e formações diversas.

Entre tantas frentes protagonizadas pelas universidades públicas na pandemia que assola também o Brasil, está também a contribuição e adaptação de iniciativas de arte e cultura para amenizar a ansiedade, depressão, entreter, e auxiliar no período de isolamento social, uma medida recomendada pela organização Mundial da Saúde - OMS, a todos os países afetados para conter a expansão do contágio do coronavírus até que se tenha uma vacina. A difusão de conteúdos, espetáculos, acervos, cursos promovidos por diferentes agentes, entre eles as universidades públicas, além de colaborar para a saúde pública e bem estar da população, amplia repertórios e permite uma aproximação das pessoas ao mundo artístico através das plataformas digitais para contornar 0 isolamento social.

\section{Estudos de caso: usos criativos de plataformas virtuais pelas IFES ${ }^{13}$}

Apesar de muitas universidades que dispõem de núcleos, departamentos e coordenações de cultura verem a necessidade de interromper suas atividades para evitar aglomerações e serem vetores de propagação do vírus, prontamente, três instituições adotaram meios alternativos e adaptaram suas programações artísticas ao formato online. A UFRGS, a UFSJ, e a UFCSPA são os três casos de universidades que iremos analisar como instituições de ensino superior que buscaram alternativas, não apenas para seguir de algum modo com a sua programação cultural, mas para contribuir para o fortalecimento das medidas de prevenção ao novo coronavirus através da arte e da

\footnotetext{
${ }^{13}$ Instituições Federais de Ensino Superior.
} 


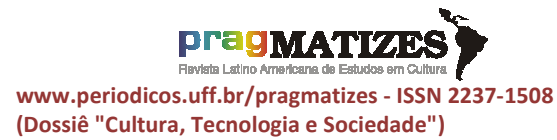

cultura. Antes mesmo de adentrarmos ao contexto da pandemia causada pelo covid-19, a OMS, em estudo recente (FANCOURT; FINN, 2019), publicou um informativo que adverte as autoridades sobre a necessidade de incluir a arte nas políticas de saúde.

Dados os benefícios que atividades dessa natureza podem acarretar ao melhoramento das condições físicas e mentais da população. Comprovando em um estudo organizado em ampla escala pela OMS que compilou dados levantados por pesquisadores de todo o mundo, os quais fundamentaram esse informativo que marcou um esforço da entidade para cobrar dos governos que apliquem melhorias na colaboração entre o setor artístico e sanitário. seguindo os indicativos da OMs, a arte pode contribuir para 0 bem estar e o combate a doenças tanto em caráter preventivo, quanto emergencial, fator que podemos observar com as diversas iniciativas no campo da arte e da cultura que se multiplicaram em canais online já no início da pandemia, como forma de evitar e/ou amenizar casos de depressão, ansiedade, e desconforto durante a prática de isolamento social. Artistas e agentes de cultura tem utilizado as novas tecnologias de informação para dar seguimento às apresentações $^{14}$ e circulação de trabalhos como peças de teatro, recitais, festivais de cinemas, exposições, musicais, oficinas artísticas, entre outras atuações.

Uma das primeiras instituições a organizar ações específicas de arte e cultura para este período de crise sanitária, como forma de contribuir para a propagação do covid-19, foi a UFCSPA. Essa universidade possui todos os seus cursos de graduação e pós-graduação e programas de pesquisa e extensão voltados para a área da saúde, porém em sua estrutura disponível no site ${ }^{15}$ encontramos o núcleo Cultural e caráter interdisciplinar e a importância que a instituição atribui a esse campo como aliado das áreas da saúde.Em decorrência de já possuir essa estrutura e uma política que inclui a arte e a cultura em seu organograma esta universidade desde o início do período de quarentena apresentou o programa 'conexão cultural UFSCPA. Uma ação que nas palavras do próprio setor possui como objetivo "contribuir para que a população atravesse este momento com mais leveza". O

\footnotetext{
${ }^{14}$ www.fundacaobienal.art.brsite da Bienal 12 do Mercosul que pela impossibilidade de realizar mostra física lança uma plataforma online para difundir a exposição de 2020.

${ }^{15}$ www.ufcspa.edu.br/index.php/nucleocultural
} 


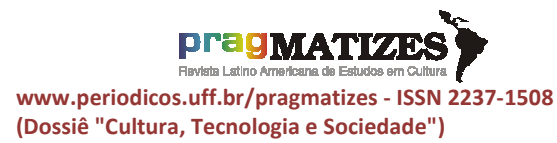

programa definido como um espaço de manifestação cultural virtual, possui três ações específicas: Na minha janela, o mundo, Palavra de Artista e Coral Virtual. Todas veiculadas nas redes ${ }^{16}$ sociais do núcleo cultural.

O programa na minha janela, 0 mundo trabalha com a linguagem da fotografia e convoca a população em geral para enviar ao setor imagens relacionadas a paisagem vivenciada pelas pessoas em quarentena. $A$ maioria das fotos enviadas $e$ publicadas nas redes culturais da UCFSPA são de pessoas vinculadas a universidade, o que demonstra que essas iniciativas, ao menos no que diz respeito a colaboração das autorias, ainda é restrita ao público acadêmico. Fato que não limita que a recepção dessas imagens possua alcance e identificação mais amplos de quem está na mesma situação, com uma visibilidade do mundo enquadrada pela janela da sua casa.

Os outros dois eixos do programa da UFCSPA, palavra de artista e banda virtual, englobam um espaço para manifestações artísticas vinculadas à instituição. No primeiro é um espaço aberto às diferentes linguagens da música, das artes visuais e da literatura que já tenham participado da agenda cultural promovida pelo setor. E o terceiro eixo é promovido por apresentações virtuais do coral da universidade. Abaixo seguem imagens que ilustram essas ações:

\footnotetext{
${ }^{16}$ Instagram, facebook e twitter Núcleo Cultural UFCSPA
} 


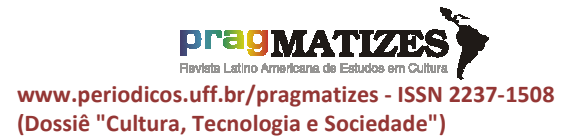

Tabela. 01 - montagem com a logo do programa e as respectivas ações
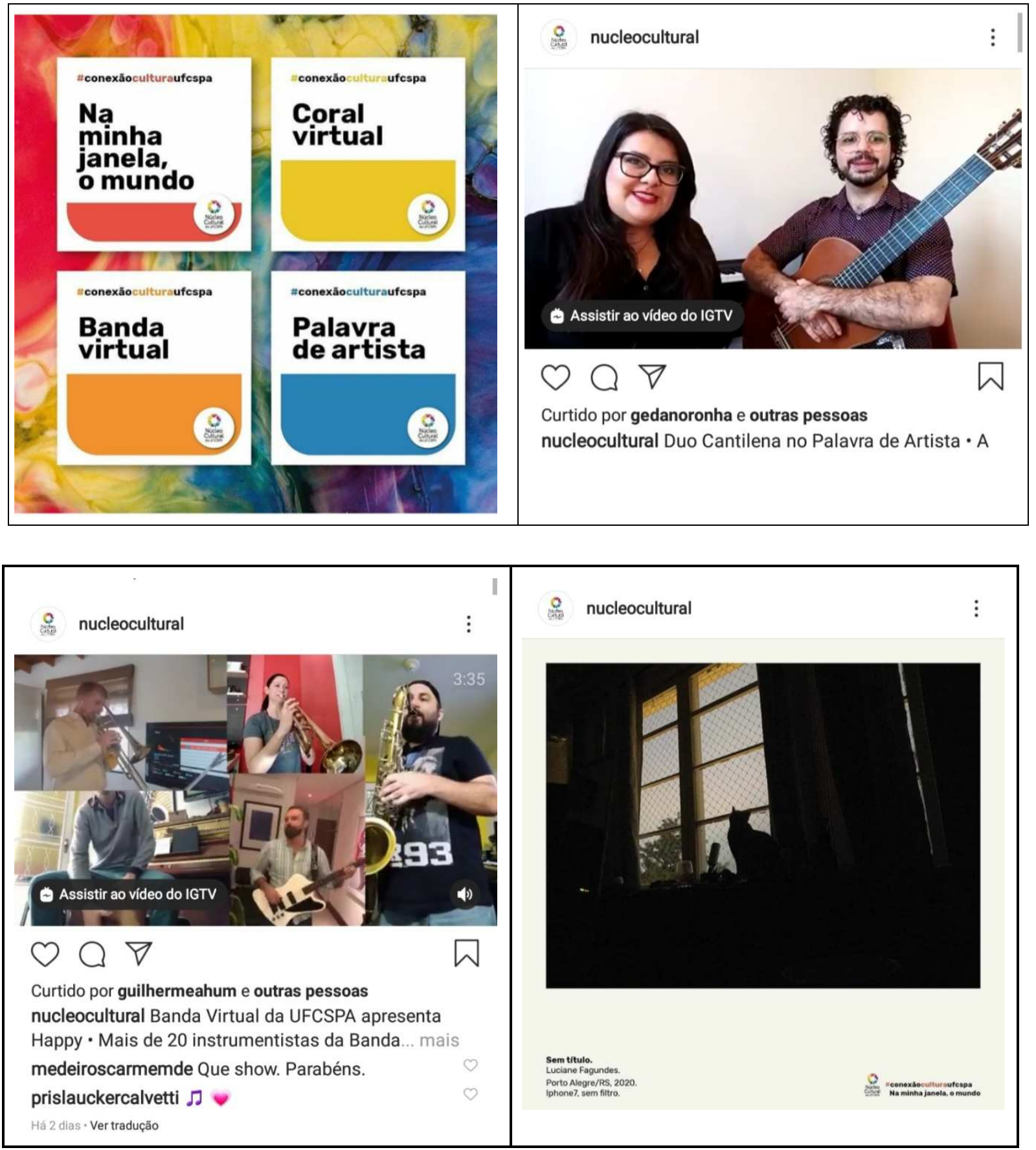

Fonte: instagram @nucleocultural e site: www.ufcspa.edu.br

Em meio à quarentena forçada em razão da pandemia de coronavírus, o Departamento de Difusão Cultural da UFRGS oferece ao público, desde março deste ano, diversas ações culturais em suas redes sociais (Facebook e Instagram). Diversas atividades como aulas de desenho e de aquarela com professoras egressas do Instituto de Artes da UFRGS como Laura Castilhos e Teresa Poester; o projeto Solo Piano, coordenado por Ney Fialkow, do Departamento de Música da 


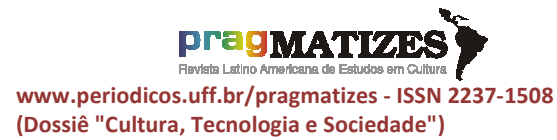

UFRGS; sugestões de filmes para você assistir; além do resgate de atividades históricas desenvolvidas pelo departamento ao longo de sua trajetória, dentre elas shows feitos no projeto Unimúsica com Luiz Melodia, Tom Zé, Arnaldo Antunes, dentre outros. (www.ufrgs.br/difusaocultural/ddcoferece-aulas-performances-eresgata-a-sua-historia-em-meio-aquarentena - grifos do original)

O texto acima é a apresentação das estratégias do departamento de difusão cultural da UFRGS em relação à condução das suas atividades durante a pandemia. Inicialmente sem uma campanha ou programa específico para o período o setor de cultura busca em seu próprio repertório adequar as ações canceladas devido ao isolamento. Em matéria anterior, no dia 13 de março, o DDC/UFRGS comunicou o cancelamento das atividades do centro cultural coordenado pelo setor e um mês depois apresentou a série de ações, citadas acima, em seu site. Podemos interpretar que inicialmente a estratégia foi interromper as ações devido às impossibilidades de realização de apresentações e oficinas em seu espaço físico, o centro cultural, porém com o tempo de algumas semanas a equipe pode encontrar nas redes sociais instagram, facebook e youtube, uma forma de seguir os trabalhos do campo das artes. O texto citado reflete bem a utilização de seu próprio repertório e acervo cultural e artístico, além de recorrer à colaboração de parceiros da própria instituição para elaborar as ações no período da quarentena.

Tabela 02. imagens da nota sobre o covid e em seguida as ações de quarentena

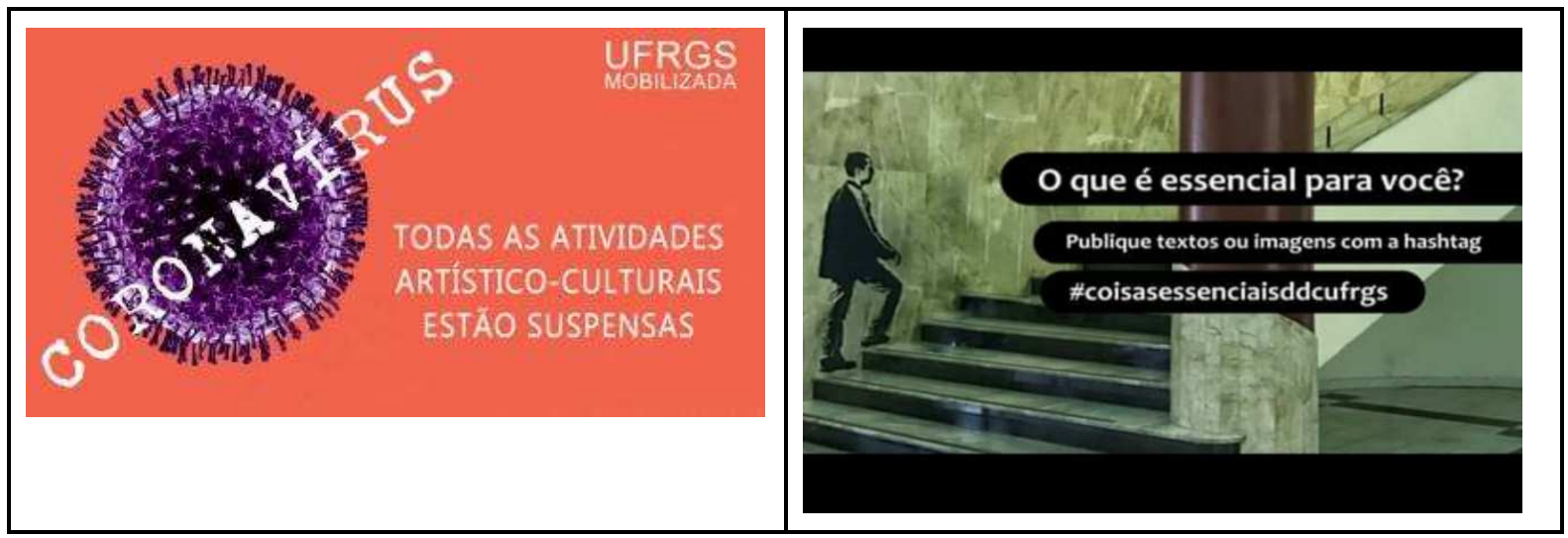




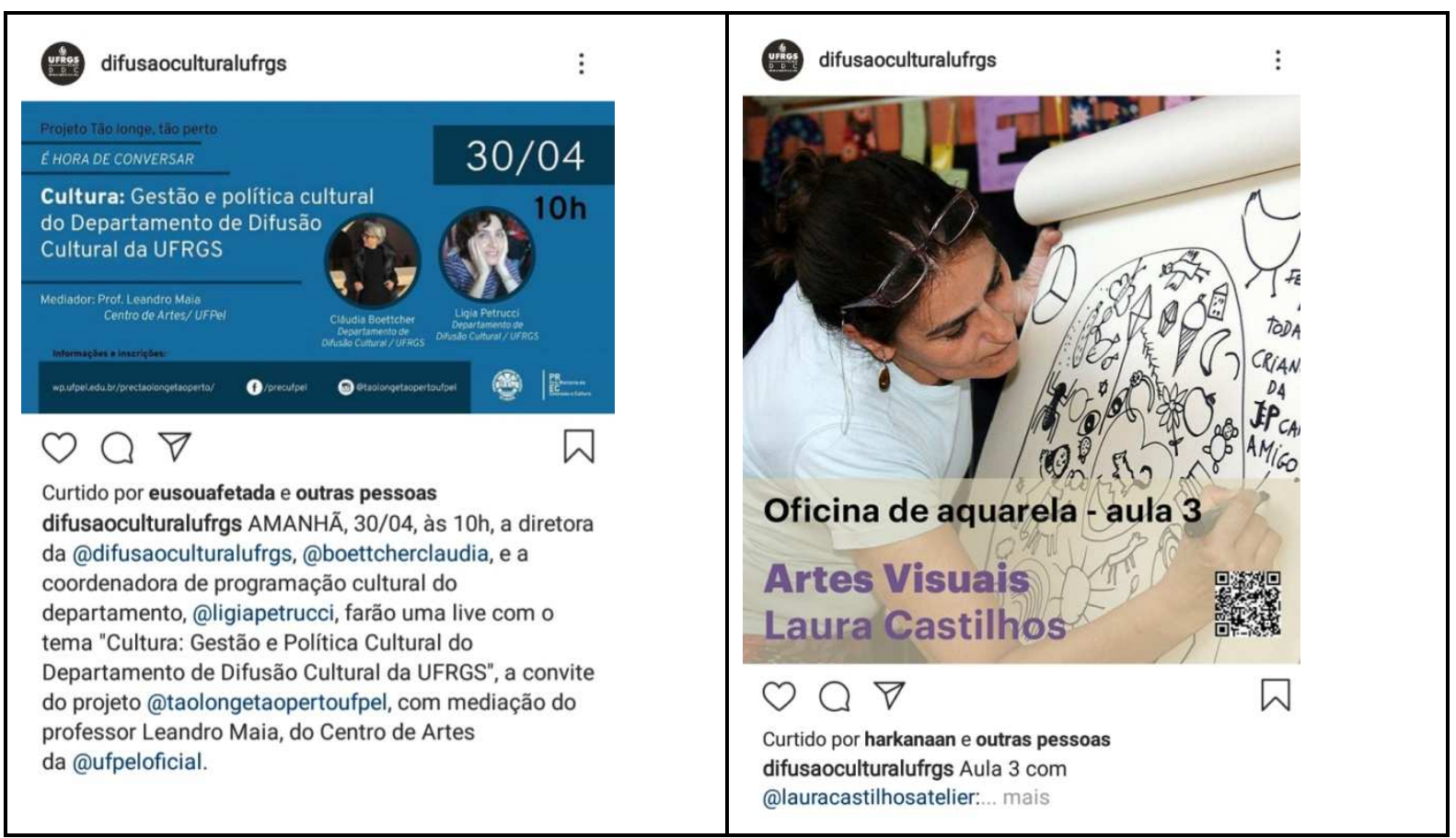

Fonte: site, instagram e facebook Difusão Cultural UFRGS

As estratégias da área de cultura foram das ações de compartilhamento de repertório e acervo cultural da universidade à campanha colaborativa \#coisasessenciaisddcufrgs. Essa ação foi recentemente lançada e demonstra que a organização cultural em tempos de pandemia é inerente ao próprio processo enfrentado pela sociedade e pode vir a multiplicar-se em diferentes desdobramentos a partir do momento em que se desloca de seu planejamento inicial.

Por fim, a última universidade que iremos retratar é a UFSJ que organizou uma atividade específica denominada por $1^{\circ}$ Festival Fica em
Casa UFSJ, ainda em março. Articulado para circular totalmente em sua página do facebook, o festival foi uma ação especificamente voltada para reagir ao isolamento enfrentado pela população diante do covid-19. além de abrir espaço para a colaboratividade inserindo em seu canal manifestações de diferentes grupos e artistas vinculados à instituição, houve ainda a preocupação em dar visibilidade à situação de precariedade que os artistas poderiam vir a enfrentar diante da crise sanitária e da ausência de políticas emergenciais voltadas para a cultura.

Diante da situação decorrente da pandemia de Covid-19, causada pelo coronavírus SARS-CoV-2, 


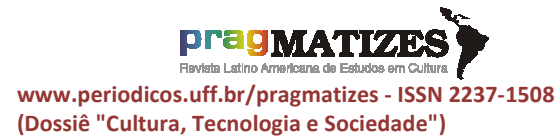

um acervo como documento e imprescindível que a população fique em casa. Após a suspensão de suas atividades e programação cultural, o Centro Cultural UFSJ, procurando reduzir os efeitos causados pelo isolamento social, criou o $1^{\circ}$ Festival Fica em Casa UFSJ. A ideia é simples: a UFSJ vem promover cultura e arte online, com conteúdo $100 \%$ gratuito. A primeira edição está planejada a partir de contação de histórias, shows, exibição de documentários e outras formas de expressão artística, além de atividades lúdicas para as crianças. O Festival quer também gerar renda para os artistas que estão sendo afetados diretamente pelas medidas restritivas de circulação. Quem se inscrever, poderá divulgar links para financiamento coletivo de suas atividades.

(www.ufsj.edu.br/noticias_ler.php?co digo_noticia=7886 - grifo do original)

As três iniciativas demonstram que a situação atípica exigiu das universidades, no que tange aos seus respectivos setores culturais, recorrer a meios alternativos disponíveis na internet. Todas elas se valeram principalmente das redes sociais para não apenas circularem seus conteúdos, como para interagirem com o público, e principalmente, com a comunidade universitária que se encontra em situação de isolamento, assim como o corpo docente e administrativo do próprio setor de cultura. É possível observar ainda que - caráter imediato da situação de emergência restringe entre os canais disponibilizados pelas instituições, salvo as que estão compartilhando seus próprios conteúdos, a criação de memória desse período a partir das expressões artísticas. Além do objetivo de vincular essas ações de cultura aos benefícios para a saúde e acolhimento da população, é importante destacar que os materiais coletados principalmente através das campanhas exclusivas deste período, como a ação na minha janela, o mundo, podem constituir objetos de memória.

A relação entre sociedade, tecnologia, e essas instituições de ensino superior por meio da difusão cultural em tempos de pandemia remete ainda ao conceito de convergência cultural de Jenkins (2009). Segundo o autor "a convergência não ocorre por meio de aparelhos, por mais sofisticados que venham a ser. A convergência ocorre dentro dos cérebros de consumidores individuais e em suas interações sociais com outros." (JENKINS, p.30, 2009). Nesse sentido, as universidades, ao utilizarem as novas tecnologias para circular seu repertório cultural passam em pouco tempo a abrir janelas para a colaboração de conteúdos, a partir dos usuários. No direção para uma estratégia mais interativa, com a inserção da campanha \#coisasessenciaisddcufrgs, na medida em que avança o caso da UFRGS é possível observar a 


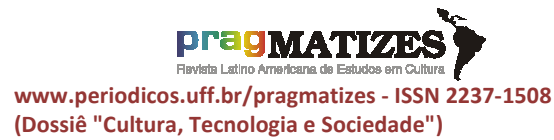

isolamento social. Já outras universidades como a UFCSPA, procurou mesclar a ação colaborativa com o compartilhamento de repertório, incluindo inclusive a possibilidade de inserção de conteúdos da população em geral. E a UFSJ, já parte da ação colaborativa, mas restringe seu alcance ao utilizar apenas um canal de suas redes sociais para o Festival.

"Em vez de falar sobre produtores e consumidores de mídia como ocupantes de papéis separados, podemos agora considerá-los como participantes interagindo de acordo com um novo conjunto de regras". (JENKINS, 2009, p.30). Em síntese, o conceito de convergência não figura um processo tecnológico que une múltiplas funções dentro dos mesmos aparelhos. Mais que isso, "é onde as velhas e as novas mídias colidem, onde a mídia corporativa e onde a mídia alternativa se cruzam, onde o poder do produtor de mídia e o poder do consumidor interagem de maneiras imprevisíveis." (JENKINS, 2009, p.29). Trazendo esse conceito para nosso estudo de casos podemos afirmar que a convergência se aplica para a conformação não apenas de instituições de ensino, comunidade, mas também para reagir e conformar o cenário de emergência sanitária em que esse processo comunicativo se inscreve.

São essas possibilidades de interação com os públicos através da formação de redes inseridas em novas mídias que podem provocar novas significações e espaços de atuação no campo da cultura. Não somente para este período de pandemia, mas em todo o contexto que surge à frente desse momento de ruptura, de revisão dos planos e com públicos que passam a ser mais segmentados, interativos, seletivos e produtores de conteúdo. As transformações proporcionadas pelas tecnologias digitais, segundo Castells (2005), sempre estiveram em nosso horizonte, mas com a pandemia provocada pelo novo coronavírus, as mudanças adquirem um caráter acelerado, muito mais que progressivo. Podemos estar cada vez mais segmentados, públicos, agentes de cultura, universidades, ainda não podemos afirmar se este contexto e seus meios poderão alterar de modo permanente valores, gostos, estilos de vida e as formas de fazer e consumir cultura.

Entretanto, nenhum avanço positivo virá sem que tenhamos incentivo e fomento público à cultura. Somente a tecnologia não dá conta de 


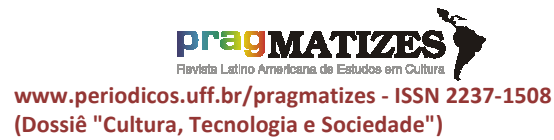

atender às demandas da sociedade, sem que tenhamos uma forma de retomar o papel das universidades públicas na democratização da cultura, que sejam elaboradas políticas públicas para que elas possam fomentar culturalmente os seus territórios. Com o covid-19 foi possível observar a importância das diferentes frentes de contribuição dessas instituições públicas de ensino superior para a sociedade, mesmo em condições de desmonte da educação. Um fator comum foi possível observar nas três ações expostas, que nenhuma delas pode disponibilizar qualquer recurso material e/ou financeiro, somente o conjunto de práticas e saberes produzidos em suas instituições, e a possibilidade de organizar campanhas, conteúdos e difundir esses materiais para melhor acolher a população em um cenário de calamidade.

\section{Considerações Finais}

A atuação das universidades públicas demonstra que mesmo as universidades que recorreram a repertórios artístico-culturais próprios ou as que buscaram intercambiar manifestações, inscrevendo suas ações em um recorte mais interativo e imediato que relaciona as expressões culturais ao período da pandemia, estão a buscar, ainda que com intenções temporárias, novas formas de praticar a difusão cultural. E mais que isso, de entender o papel da cultura para a sociedade e suas próprias instituições de ensino superior. Perpetuaram ações, abrindo mão de planejamentos de atividades previamente estabelecidos, contornando a escassez de recursos humanos, financeiros em suas reduzidas equipes para se apropriarem das possibilidades das novas tecnologias, as mesmas que são mecanismos de sustentação de eixos de dominação da sociedade.

Quando falamos nesses campos de domínio estamos nos referindo aos mesmos grupos que investem em discursos que deslegitimam a existência e a atuação das universidades públicas. O capital financeiro e privatizador que domina a mídia comercial, também detém os espaços proporcionados pelas novas tecnologias, porém não totalmente. Há sempre fendas para perpetuar as práticas de resistência e organizarem formas de sobrevivência em meio ao caos, e às políticas de desmonte dos bens públicos. Ainda assim, as novas tecnologias, a depender de seus usos e de sua apropriação, podem fazer 
ressoar vozes invisibilizadas, instituições deslegitimadoras e fortalecer o bem comum em benefício da sociedade. Além disso, nosso estudo pontua a necessidade de as universidades serem alvos de políticas públicas de cultura, pois possuem capacidade e permeabilidade em seus territórios, para fomentar 0 desenvolvimento cultural local, além de serem instituições com potencial e conexões capazes de propagar essas ações e manifestações locais a nível global, alçando territórios e suas comunidades para outros patamares.

\section{Referências Bibliográficas}

CASTELLS, Manuel. A Sociedade em Rede. São Paulo: Paz e Terra, 2005.

CASTELLS, Manuel. Comunicación y Poder. Madrid: Alianza Editorial, 2009.

FANCOURT, Daisy; FINN, Saoirse, Health Evidence Network synthesis report 67: What is the evidence on the role of the arts in improving health and well-being? A scoping review, WHO (World Health Organization), Regional Office for Europe, 2019.

FRAGOSO, Suely; RECUERO, Raquel; AMARAL, Adriana. Métodos de pesquisa para internet. Porto Alegre: Sulina, ed.1, 2012.

GOBIRA, Pablo; ROLLA, Marco Paulo; SIMON DA SILVEIRA, Yuri, LEMOS, Flávia. Arte e cultura na universidade: passos na construção de uma política de cultura, In: (orgs.). Refletindo sobre a cultura: Política cultural, memória e universidade, Belo Horizonte: EduEMG, 2017. p. 138-160.
JENKINS, H. Cultura da Convergência. São Paulo: Aleph, 2009.

LEHER, Roberto. Autoritarismo contra a Universidade: $O$ desafio de popularizar a defesa da educação pública. São Paulo: Fundação Rosa Luxemburgo, Expressão Popular, 2019.

LEMOS, A; LÉVY, P. O futuro da internet: em direção a uma ciberdemocracia planetária. São Paulo: Paulus, 2010. 